\title{
Development of a multi-dimensional measure of resilience in adolescents: the Adolescent Resilience Questionnaire
}

\author{
Deirdre Gartland ${ }^{1 *}$, Lyndal Bond ${ }^{2}$, Craig A Olsson ${ }^{3}$, Simone Buzwell ${ }^{4}$ and Susan M Sawyer ${ }^{5}$
}

\begin{abstract}
Background: The concept of resilience has captured the imagination of researchers and policy makers over the past two decades. However, despite the ever growing body of resilience research, there is a paucity of relevant, comprehensive measurement tools. In this article, the development of a theoretically based, comprehensive multidimensional measure of resilience in adolescents is described.

Methods: Extensive literature review and focus groups with young people living with chronic illness informed the conceptual development of scales and items. Two sequential rounds of factor and scale analyses were undertaken to revise the conceptually developed scales using data collected from young people living with a chronic illness and a general population sample.

Results: The revised Adolescent Resilience Questionnaire comprises 93 items and 12 scales measuring resilience factors in the domains of self, family, peer, school and community. All scales have acceptable alpha coefficients. Revised scales closely reflect conceptually developed scales.

Conclusions: It is proposed that, with further psychometric testing, this new measure of resilience will provide researchers and clinicians with a comprehensive and developmentally appropriate instrument to measure a young person's capacity to achieve positive outcomes despite life stressors.
\end{abstract}

\section{Background}

Resilience has been variously defined as positive developmental outcomes in the face of adversity or stress $[1,2]$; being relatively resistant to psychosocial risk experiences [3], successful adaptation or the development of competence despite high-risk status or chronic stress [4] and the capacity of dynamic systems to withstand or recover from significant disturbances [5]. While differing in terminology, such definitions describe the two common factors necessary for defining resilience; firstly the experience of adversity or stress, and secondly, the achievement of positive outcomes. While resilience research continues to grow, there have been few attempts to integrate current knowledge into measurement tools. In this paper, the development and pilot

\footnotetext{
* Correspondence: deirdre.gartland@mcri.edu.au

'Healthy Mothers Healthy Families Research Group, Murdoch Children's

Research Institute, Melbourne, Australia

Full list of author information is available at the end of the article
}

testing of a comprehensive and theoretically based measure of resilience for adolescents is detailed.

Early research identified resilience as a characteristic of the individual [6], and considered resilient children to be exceptional individuals, unique in their ability to prevail against the odds. Current research now predominantly views resilience as the process by which individuals draw on personal characteristics and resources in their environment to enable them to successfully negotiate adversity [1,7-10]. As such, resilience is not seen as a static characteristic of an individual, but rather a dynamic process across contexts and throughout the life span. The process of resilience can be seen as arising from interactions which are central to normal developmental processes that commonly occur and may even be seen as 'ordinary' [1].

A range of factors commonly associated with resilient outcomes have been widely studied and described. While the literature around the concept of resilience is increasing, there have been few attempts to synthesise
C Biomed Central 
current research findings into useful measurement tools. The issue with most current measures of resilience is their limited focus, for example, only addressing individual characteristics [11-13]. Other resilience measures have included some environmental factors but are limited in scope and detail [14]. Research findings indicate that resilience is a multi dimensional construct - resilience in one domain does not automatically confer resilience in other domains $[15,16]$. Thus it is vital to examine resilience more broadly. Other limitations of currently available resilience measures include: a lack of a clearly defined definitions/models of resilience and/or theoretical underpinning; flawed development processes; limited breadth (most cover individual factors only]; and/or inadequate psychometric properties [17]. This paper reports on the development of a new measure of adolescent resilience that: 1) encompasses the full range of individual factors associated with resilient outcomes; 2 ) includes assessment of resilience factors in the wider social environment; 3) is developmentally appropriate for adolescents; and 4) builds on a clearly defined theoretical framework or model of resilience.

\section{Development of the Adolescent Resilience Questionnaire}

An ecological-transactional model $[18,19]$ was used to provide a conceptual framework for integrating the individual and environmental factors underlying resilience. This model describes an individual's environment as nested levels of increasing proximity - from societal cultural beliefs and values, to neighbourhood and community settings, then family environment and finally the individual [19]. In this model "context and children's functioning are conceptualised as mutually influencing each other" p. 236 [18]. Each level of the environment contains risk and protective factors for the individual and these factors can be transient or enduring. In this context, examination of resilience factors in each nested level is required to develop a comprehensive measure. Salient adolescent ecological 'levels' have been identified as the domains of individual, family, peers, school and community $[10,20]$. Resilience factors in each of these domains were examined and factors associated with better outcomes for young people facing adversity were identified.

A detailed literature review in each of the five domains [17] was supplemented by focus group discussions with adolescents living with a chronic illness recruited from a peer support program [21] and a hospital adolescent ward in order to identify resilience factors to be included in the new measure (see Table 1). Chronically ill adolescents represent an ideal group in which to explore notions of resilience as they face varying levels of adversity in their day to day lives. These adolescents have been shown to be at greater risk of poor outcomes including increased social difficulties, health risk behaviours and mental health states including low self esteem and poor body image [22-27]. However, the majority show positive outcomes, particularly those with less severe illness and without corresponding physical disability $[28,29]$. Focus group discussions were thematically analysed to derive resilience themes. The primary themes derived from the focus groups fitted well with resilience factors identified in the literature and were developed into 14 conceptual scales across the five domains of self, peers, family, school and community (see Figure 1).

The family, peer, school and community domain conceptual scales are self explanatory but some discussion is merited for the individual domain. Emotion regulation and control beliefs: Positive emotion regulation skills involve processes by which positive emotionality is maximised or negative emotionality, emotional lability and inappropriate affect minimised. Significant associations have been reported between positive emotion regulation and resilience [30,31], concurring with broader non resilience research supporting the role of emotion regulation and positive outcomes for children [32-34]. A positive association between internal locus of control and resilience has been well documented [35-38]. For example, maltreated children with an internal locus of control were twice as likely to be classified as resilient compared to children with an external locus of control [39].

\section{Introspection and reflection}

This was a strong theme arising from the focus groups that was not identified in resilience literature review. Chronically ill adolescents described the importance of having the time and space to think things through, to work out what was happening and why, the meaning behind events. Adolescents identified this as an important factor in their resilience.

\section{Social skills (General and Empathy)}

Social skills have been described as the interpersonal behaviours needed to develop and deepen supportive personal relationships [40] and have wide ranging implications for healthy development throughout the life span $[41,42]$. It is unsurprising that social skills have been associated with greater likelihood of resilient outcomes [43]. For example having a positive, reciprocal friendship increased the likelihood of resilience in maltreated children [39]. Resilient young people have been found to have higher empathy and more effective social problem solving skills than those who were stress-affected $[36,44]$.

\section{Optimism/Positive Future expectations}

A positive sense of the future can be conceptualised as "expectations of attaining specific objectives (e.g. 
Table 1 Study participant numbers, gender and age

\begin{tabular}{|c|c|c|c|c|}
\hline & \multirow{2}{*}{$\begin{array}{c}\text { Participants } \\
\text { n }\end{array}$} & \multirow{2}{*}{$\begin{array}{c}\text { Female } \\
\%\end{array}$} & \multicolumn{2}{|c|}{ Age (years) } \\
\hline & & & Range & Mean (SD) \\
\hline \multicolumn{5}{|l|}{ Focus Groups with chronically ill adolescents } \\
\hline \multicolumn{5}{|l|}{ Peer support group members } \\
\hline Metropolitan (3 groups) & 14 & 79 & $15-22$ & \\
\hline Regional Victoria (1 group) & 6 & 67 & $14-24$ & \\
\hline Hospital ward (1 group) & 4 & 50 & 19 & \\
\hline Total focus group sample & 24 & 71 & $14-24$ & $18.6(2.5)$ \\
\hline \multicolumn{5}{|l|}{ Pilot testing of the $A R Q$} \\
\hline Catholic secondary school students & 330 & 60 & $13-16$ & $14.3(0.49)$ \\
\hline \multicolumn{5}{|l|}{ Adolescents with a chronic illness } \\
\hline \multicolumn{5}{|l|}{ Hospital Clinics } \\
\hline Asthma & 31 & 58 & $12-17$ & \\
\hline Neurology & 4 & 50 & $15-17$ & \\
\hline Cystic Fibrosis & 73 & 51 & $11-18$ & \\
\hline Rheumatology & 23 & 91 & $12-18$ & \\
\hline Adolescent Ward & 13 & 69 & $13-18$ & \\
\hline \multicolumn{5}{|l|}{ Support Groups } \\
\hline Diabetes & 7 & 71 & $14-16$ & \\
\hline Epilepsy & 13 & 62 & $14-17$ & \\
\hline Peer support group (Non illness specific) & 40 & 58 & $12-18$ & \\
\hline Total & 204 & 60 & $11-18$ & $14.9(1.8)$ \\
\hline Total pilot testing sample & 534 & 60 & $11-18$ & $14.5(1.2)$ \\
\hline \multicolumn{5}{|l|}{ Revision of the ARQ } \\
\hline \multicolumn{5}{|l|}{ Random sample secondary schools } \\
\hline Year seven & 191 & 48 & $11-14$ & $12.4(0.5)$ \\
\hline Year nine & 260 & 51 & $14-17$ & $14.9(0.6)$ \\
\hline Total revision sample & 451 & 50 & $11-17$ & $13.9(1.4)$ \\
\hline
\end{tabular}

achieving in school, having close friends) in later developmental periods" [45] while optimism can be defined as a general expectation of positive outcomes. The two concepts have been shown to be positively correlated and have both been identified as distinguishing resilient children from those affected by stress [7,44,46-50].

\section{Problem solving}

Problem solving abilities have been linked to resilient children compared to their non-resilient peers [35,37,51-53] and have been identified as promoting resilient outcomes in a range of risk situations including poverty and abuse [54], homelessness [31], cancer survivors and parents with a mental illness [55], and depression [56].

A large item pool for each scale was written according to the guiding principals for item development as described by Kline [57] and Streiner and Norman [58]. Consultation with a team of adolescent clinicians and researchers was then used to select the best items for each scale. In this paper, the pilot testing (Study 1) and revision (Study 2) of the newly developed Adolescent
Resilience Questionnaire [ARQ] are described. As Study 1 and 2 were identical in method, the common method is reported first and then results for each study are detailed in turn.

\section{Methods}

\section{Participants}

Participants were recruited through Government and Catholic secondary schools, chronic illness support groups, and hospital clinics. Participation required written parent and participant consent.

School students were given a letter explaining the purpose and procedure of the study and parent and participant consent forms. Students who returned signed consent forms completed the paper ARQ questionnaire during class time.

Chronic illness support group members and hospital clinic patients were sent a letter explaining the purpose and procedure of the study, consent forms and the ARQ questionnaire. Completed consent forms and questionnaires were returned separately in the reply paid envelopes provided. After three weeks, reminder letters and 


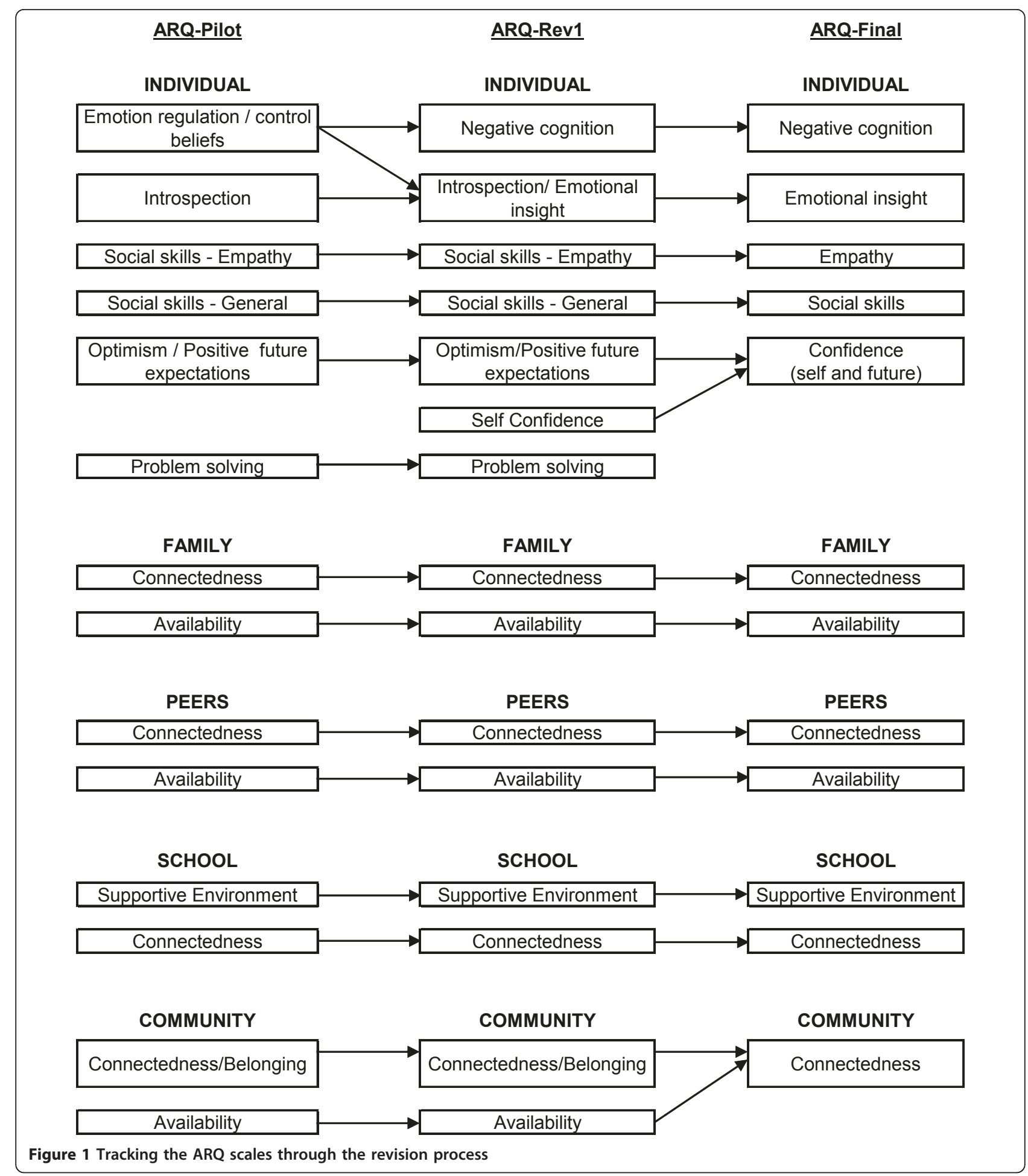

replacement forms and questionnaires were sent to all nonrespondents.

Ethics approval was granted from Swinburne University, The Royal Children's Hospital, Department of Education, Employment and Training ethics committees and the Catholic Education Office.

\section{Materials}

The ARQ is a pen and paper questionnaire with scales in five domains: individual, family, peers, school and community. Items comprise statements with a five point Likert response scale labelled: 1 Never, 2 Not often, 3 Sometimes, 4 Most of the time and 5 All the time. 
Higher scores indicate greater resilience. A space was available at the end of each domain for participants to write comments regarding items or the questionnaire.

\section{Analysis \\ Item analysis}

Questionnaire items were deleted or revised if they were: identified by respondents as difficult to understand; considered by the researcher to have poor face validity; or endorsed by less than $20 \%$ or more than $80 \%$ of respondents [26,27].

\section{Scale analysis}

Factor and reliability analyses were used to guide the construction of scales and selection of the best items. Factor analyses were conducted within each domain with maximum likelihood extraction and oblimin rotation to accommodate possible correlation between factors [28]. Initial eigenvalues and scree plots were employed to select the number of factors. The most parsimonious factor solution was selected according to the following criteria: a good conceptual fit, high percentage of variance explained, high factor loading scores with minimal cross loading and stability of factors across different solutions. Factors were used to construct scales where more than three items loaded at 0.4 or higher and up to eight items were retained per scale. Items loading below 0.3 or on more than one factor were deleted. Internal consistency was assessed using Cronbach alpha. Newly developed scales were examined to ensure fidelity to the original concept, and new items written to fill any gaps in face and content validity or to improve reliability. New items were written following the guiding principals elaborated by Kline [57] and Streiner and Norman [58], drawing on the conceptual underpinning of the scale and taking into account items that had failed to perform during the revision process.

\section{Results}

\section{Study 1 - Pilot testing of the ARQ Participants}

Two samples completed the pilot ARQ. 1) A convenience sample of year 9 students attending Catholic schools in Victoria, Australia. Eleven of the 45 schools invited agreed to participate and 330 of the 1031 eligible students (32\% response rate) completed the pilot ARQ (see Table 1). 2) Adolescents with chronic illness were recruited from support groups and hospital clinics. Recruitment from hospital clinics and community support groups ensured the inclusion of adolescents with a range of illness severity. Chronic illnesses included asthma, cystic fibrosis, arthritis, diabetes, lupus and epilepsy. Two hundred and forty seven of the 437 adolescents invited to participate returned the ARQ (57\% response rate). Forty three respondents were ineligible as they were over 18 years of age, which left a total of 204 adolescents with a mean age of 14.9 years (see Table 1).

Analysis

Seven items commonly identified as difficult to understand and seven items with endorsement of less the 20\% or greater than $80 \%$ were deleted. Factor solutions were found to be almost identical in the chronic illness and school samples so the data were combined to increase sample size $(\mathrm{n}=534)$. Factors closely reflected the conceptually developed scales and explained the majority of the variance in all solutions with the exception of the individual and community domains, where the most revision occurred (data available in additional files as detailed below).

In the individual domain the six factor scales resembled the six conceptually derived scales (see additional file 1 for factor output for the individual domain), however a number of important differences were identified and acted upon (see Figure 1). The emotion regulation factor scale appeared more focussed on negative cognition, due in part to the positive emotion regulation items loading on the optimism/positive future expectation factor scale. Therefore, it was decided to:

- Rename the emotion regulation factor scale negative cognition and add new items to cover negative emotion regulation more comprehensively.

- Add new items to the optimism/positive future expectation scale to more closely reflect the construct.

- Expand the introspection/meaning scale to include items addressing positive emotion regulation and rename the scale introspection/emotional insight, as these items are conceptually a better fit here than in the optimism/positive future expectation factor scale.

New items were added accordingly and a number of items were rewritten in the remaining scales so that items reflected the underlying construct more closely or to simplify the language. As described in the method section above, new items were written following the guiding principals elaborated by Kline [57] and Streiner and Norman [58], drawing on the conceptual underpinning of the scale and taking into account items that had failed to perform. In the family, peer and school domains, the conceptual scale structure of connectedness and availability of support was replicated by the factor analysis (see additional files 2, 3, 4 for factor output for family, peer and school domains). There was some movement of individual items between scales and some items were rewritten to be more specific and less positive in order to improve the face and content validity. In the community domain the two conceptually developed 
scales were supported by the factor structure (see additional file 5 for factor output for community domain), but were highly correlated $(\mathrm{r}=0.7)$. Revision of these scales therefore focused on developing scales that tapped more discrete constructs by drawing on the sense of community and social capital literature (see [59-61]). The connectedness scale already covered sense of community, addressing adolescents' perception of belonging and attachment to their neighbourhood. Therefore the support availability scale was broadened with the addition of new items aimed at encompassing social capital concepts of trust, obligation and sanction [61].

Following this process, the pilot ARQ was revised to create the ARQ-Revision 1 (ARQ-Rev1) which was comprised of six scales and 79 items in the individual domain, and two scales each in the family (20 items), peer (11 items), school (15 items) and community (15 items) domains. Whilst the ARQ-Rev1 was relatively long (140 items in total), being over inclusive at this stage of development facilitated selection of the best items and scales in the second phase of data collection and revision described in Study 2.

\section{Study 2 - Revision of the ARQ-Rev 1 to create a brief functional measure of resilience \\ Participants}

Eleven of 12 secondary schools randomly selected from all Victorian Government schools agreed to participate in the study. Two classes from years seven and nine were randomly selected within each school ${ }^{1}$. A total of 451 of 982 eligible students (50\% response rate) completed the questionnaire during class time. Students had a mean age of 13.9 years (see Table 1).

Analysis

Two items commonly seen as difficult to understand and nine items with endorsement of less than $20 \%$ or more than $80 \%$ were deleted.

In the individual domain, the 5 -factor solution was selected as the most parsimonious as described in the above methods section (see additional file 6 for factor output for the individual domain). Major similarities and differences were:

- Four factors closely resembled the ARQ-Rev1 scales of negative cognition, empathy, social skills and emotional insight/introspection and were labelled accordingly.

- Items from the ARQ-Rev1 self-confidence and optimism/positive future expectation scales loaded on a single factor. This factor was therefore labelled confidence (self and future) (see Figure 1).

- The ARQ-Rev1 problem solving scale was not supported by the factor analysis, with problem solving items loading on various factors in the solution.

The five factors were used to construct scales following the steps described in the method. Following this revision process the individual domain consisted of the five scales negative cognition, confidence (self and future), emotional insight, empathy/tolerance and social skills. The scales contained six to eight items and, as shown in Table 2, scale reliabilities ranged from adequate to very good. Two new items were added to the empathy and

Table 2 ARQ scales, example item and reliability score

\begin{tabular}{|c|c|c|c|}
\hline DOMAIN Scale & Sample item & Number of items & Reliability (Cronbach $\alpha$ ) \\
\hline \multicolumn{4}{|l|}{ INDIVIDUAL } \\
\hline Confidence (self/future) & I feel confident that I can handle whatever comes my way & 8 & 0.8 \\
\hline Emotional insight & I think things through carefully before making decisions & 8 & 0.7 \\
\hline Negative cognition & I tend to think the worst is going to happen (reversed) & 8 & 0.8 \\
\hline Social skills & I can express my opinions when I am in a group & 8 & 0.7 \\
\hline Empathy/Tolerance & I am patient with people who can't do things as well as I can & 8 & 0.7 \\
\hline \multicolumn{4}{|l|}{ FAMILY } \\
\hline Connectedness & I enjoy spending time with my family & 8 & 0.9 \\
\hline Availability & There is someone in my family I can talk to about anything & 3 & 0.8 \\
\hline \multicolumn{4}{|l|}{$\underline{\text { PEERS }}$} \\
\hline Connectedness & I have a friend I can trust with my private thoughts and feelings & 7 & 0.8 \\
\hline Availability & I wish I had more friends | felt close to (reversed) & 8 & 0.6 \\
\hline \multicolumn{4}{|l|}{$\underline{\mathrm{SCHOOL}}$} \\
\hline Supportive Environment & My teachers are caring and supportive of me & 8 & 0.8 \\
\hline Connectedness & I try hard in school & 8 & 0.7 \\
\hline \multicolumn{4}{|l|}{$\underline{\text { COMMUNITY }}$} \\
\hline Connectedness & I trust the people in my neighbourhood & 6 & 0.9 \\
\hline
\end{tabular}


social skills scales with the intention of improving scale reliability. The items were written as described in the method section above, drawing on the conceptual underpinning of the scale and taking into account items that had failed to perform in the previous two revisions.

In the family domain, the two factor solution closely replicated the ARQ-Rev1 scales of connectedness and availability and was labelled accordingly (see additional file 7 for factor output for the family domain). The two factors were used to construct scales with excellent reliability (see Table 2). The connectedness scale assesses a nurturing and supportive family environment, while the second scale assesses the availability of family members for support or advice. The two family scales were highly correlated $(\underline{r}=0.66)$ indicating that adolescents' scores on family connectedness will generally correspond to their scores on the availability scale. Similarly, the factor analysis in the peer domain closely replicated the ARQRev1 peer connectedness and availability scales (see additional file 8 for factor output for the peer domain). The connectedness scale covers feeling connected to friends and confidence with peers, while the availability scale (reversed) taps into the ability to form and maintain friendships. The connectedness scale had excellent reliability; however, the reliability of the three item availability scale fell below the target range of $0.7-0.9$. Therefore five new items were written to create an eight-item scale with the intention of improving reliability.

The factor analysis in the school domain closely replicated the ARQ-Rev1 supportive environment and connectedness scales (see additional file 9 for factor output for the school domain). Items in the supportive environment scale refer to student and staff factors that impact on the general school environment. The connectedness scale (reversed) contains items related to an adolescents' feelings of commitment and connection to school both social and academically. Four new items were added to the connectedness scale to make an eight-item scale, with the intention of balancing the scale with positive items and improving the reliability coefficient.

Efforts to address the multiple facets of community support and belonging as explored in the sense of community and social capital literature failed to be supported by the factor analysis in the community domain. The data consistently identified a single factor, seemingly addressing general community connectedness (see additional file 10 for factor output for the community domain). The eight item community scale had a Cronbach alpha coefficient greater than 0.90 , suggesting excessive consistency or repetitive items in the scale [62]. Two items were therefore deleted to produce a sixitem scale with excellent reliability (see Table 2). The community connectedness scale assesses networks of support and engagement within the community.
The revised ARQ comprises six scales in the individual domain, two scales in each of the family, peer, and school domains and a single community scale with 88 items in total.

\section{Discussion}

While the literature around the concept of resilience is increasing, there have been few attempts to synthesise current research findings into useful measurement tools. The newly developed ARQ is a relatively short and easy to administer questionnaire which identifies the resources available to an adolescent, both individually and in their wider social environment. The ARQ can assist in identifying adolescents who have personal characteristics associated with resilience (confidence, social skills, emotional insight and negative cognition) and who are positively engaged with their family, peers, school and community environments. Arguably, such adolescents are more likely to show resilient outcomes in times of adversity. Conversely, the ARQ can identify adolescents who show poor engagement in all or some of these areas and who may be vulnerable in the face of adversity.

The ARQ scales identified in the factor analyses show notable conceptual similarity to the constructs initially proposed for measurement (drawn from the resilience literature and focus groups). However some scales were not supported by the statistical analysis. For example, the problem solving scale failed to form a unique factor, with items loading on the social skills and emotional insight factors, and was ultimately subsumed into these two scales. This may reflect poor construct operationalisation or be a true reflection of the adolescent experience. Resilience literature supports the latter, reporting significant positive associations between problem solving skills and both social skills and emotion regulation in childhood, adolescence and adulthood [31,33,63-65]. Thus, problem solving skills may not operate as a singular competency but underlie other resilience factors, such as emotional insight and social skills, and be context specific.

The identification of the negative cognition factor was unexpected and without precedence in other resilience measures. Many of the negative cognition items were negatively worded and were intended to gauge deficits in self efficacy, confidence and optimism/hope. Few resilience measures have included negative items as they generally assess possession of a resource rather than a deficit. This factor appears to address a sense of helplessness and low internal locus of control. Children identified in the Rochester Child Resilience Project as stress-affected [36] evidenced such characteristics - they had significantly lower scores than both stress-resilient children and non-classified children on problem solving, 
coping and internal locus of control. Thus, conceptually, the negative cognition scale defines vulnerable adolescents, such that high scores on this scale would be expected to be associated with low resilience. Further testing and comparison with other measures of resilience will add to the understanding of this scale.

The two family scales were highly correlated indicating that adolescents' scores on family connectedness will generally correspond to their scores on the availability scale. It may therefore be preferable to use only one of these two scales. However, the items loaded cleanly on separate factors in the analysis, suggesting the scales tapped into different constructs. Further investigation, including tests of construct validity, will allow an informed decision to be made as to whether to retain both scales or to retain one scale and decrease of the length of the measure - a desirable goal in scale development.

The ARQ is at an early stage of development and further psychometric testing is necessary. For example, the comparison of ARQ scores and relevant sub-scales with other resilience measures, and comparison of subscales with gold standard measures of similar concepts such as coping and social support will provide evidence of criterion validity. Examination of ARQ scores for identified stress-resilient and stress-affected populations will indicate how well the ARQ discriminates between populations. Focus groups and administration of the questionnaire to over 500 adolescents in total have shown the questionnaire to be easy for adolescents to understand and complete. The factor and scale analyses revealed a stable factor structure that was conceptually convincing and true to the original intent of the measure. While the ARQ is presented as a functional measure of resilience in adolescents, evidence of scale and test-retest reliability, criterion validity and sensitivity to change will enhance understanding of and confidence in the measure's psychometric properties.

The ARQ has been developed to identify adolescents who have personal characteristics associated with resilience, and who are positively engaged with their family, peers, school and community environments. Such adolescents are more likely to show resilient outcomes in times of adversity. Conversely, the ARQ can identify adolescents who show deficits or poor engagement in all or some of these areas, who may be vulnerable in the face of adversity. The availability of developmentally appropriate, multidimensional measurement tools will facilitate resilience researchers in their 'central mission' as described by Luthar and Brown "... to illuminate processes that significantly mitigate the ill effects of various adverse life conditions as well as those that exacerbate these, and thus to derive specific directions for interventions and social policies" [66].

\section{Conclusions}

The ARQ was developed in response to a distinct lack of measurement tools in resilience research generally and for adolescents in particular. Greater scientific rigour and consistency in measurement tools and approaches will contribute to improved understanding of the complex processes involved in resilient responses to adversity. The availability of standard measures in resilience research, such as the ARQ, will make comparisons across studies and risk groups possible. With further psychometric testing, this new measure of resilience will provide researchers and clinicians with a comprehensive and developmentally appropriate instrument to measure a young person's capacity to achieve positive outcomes despite life stressors.

\section{Endnotes}

${ }^{1}$ With the exception of one rural school where an unforeseen school event determined that year 7 classes were unavailable at the prearranged time and all year nine students were surveyed instead. We were unable to arrange another time due to school commitments and ethics requirements prohibited the substitution of another year level.

\section{Additional material}

\footnotetext{
Additional file 1: Study 1 Factor solution individual domain. Study 1

output describing factor analysis of the individual domain. Output includes the initial statistics for the six-factor solution with oblimin rotation, and the rotated factor loadings with the original conceptual scales, and factor developed scales described.
}

Additional file 2: Study 1 Factor solution family domain. Study 1 output describing factor analysis of the family domain. Output includes the initial statistics for the two-factor solution with oblimin rotation, and the rotated factor loadings with the original conceptual scales, and factor developed scales described.

Additional file 3: Study 1 Factor solution peer domain. Study 1 output describing factor analysis of the peer domain. Output includes the initial statistics for the two-factor solution with oblimin rotation, and the rotated factor loadings with the original conceptual scales, and factor developed scales described.

Additional file 4: Study 1 Factor solution school domain. Study 1 output describing factor analysis of the school domain. Output includes the initial statistics for the two-factor solution with oblimin rotation, and the rotated factor loadings with the original conceptual scales, and factor developed scales described.

Additional file 5: Study 1 Factor solution community domain. Study 1 output describing factor analysis of the community domain. Output includes the initial statistics for the two-factor solution with oblimin rotation, and the rotated factor loadings with the original conceptual scales, and factor developed scales described.

Additional file 6: Study 2 Factor solution individual domain. Study 2 output describing factor analysis of the individual domain. Output includes the initial statistics for the five-factor solution with oblimin rotation, and the rotated factor loadings with the original conceptual scales, and factor developed scales described.

Additional file 7: Study 2 Factor solution family domain. Study 2 output describing factor analysis of the family domain. Output includes the initial statistics for the two-factor solution with oblimin rotation, and 
the rotated factor loadings with the original conceptual scales, and factor developed scales described.

Additional file 8: Study 2 Factor solution peer domain. Study 2 output describing factor analysis of the peer domain. Output includes the initial statistics for the two-factor solution with oblimin rotation, and the rotated factor loadings with the original conceptual scales, and factor developed scales described.

Additional file 9: Study 2 Factor solution school domain. Study 2 output describing factor analysis of the school domain. Output includes the initial statistics for the two-factor solution with oblimin rotation, and the rotated factor loadings with the original conceptual scales, and factor developed scales described.

Additional file 10: Study 2 Factor solution community domain. Study 2 output describing factor analysis of the community domain. Output includes the initial statistics for the two-factor solution with oblimin rotation, and the rotated factor loadings with the original conceptual scales, and factor developed scales described.

\section{Acknowledgements}

Deirdre Gartland completed her Doctorate in Psychology [Health] at Swinburne University, with financial support provided by the Murdoch and Childrens Research Institute in the form of a Trainee Research Scholarship, based at the Centre for Adolescent Health. This work was also supported by funding from Bluey Day Victoria. We wish to thank Michelle Doolin for her assistance in organising and collecting data from the Catholic schools in the pilot study.

\section{Author details}

'Healthy Mothers Healthy Families Research Group, Murdoch Children's Research Institute, Melbourne, Australia. ${ }^{2}$ Social and Public Health Sciences Unit, Medical Research Council/Chief Scientist Office, Glasgow, UK. ${ }^{3}$ Centre for Adolescent Health, Murdoch Childrens Research Institute, Melbourne, Australia: Psychological Sciences and Department of Paediatrics, The University of Melbourne, Melbourne, Australia: School of Psychology, Deakin University, Geelong, Australia. ${ }^{4}$ Swinburne Professional Learning, Swinburne University, Melbourne, Australia. ${ }^{5}$ Centre for Adolescent Health, Royal Children's Hospital, Melbourne, Australia; Murdoch Children's Research Institute, Melbourne, Australia; Department of Paediatrics, The University of Melbourne, Melbourne, Australia.

\section{Authors' contributions}

DG participated in the design of the studies, coordinated and carried out data collection, performed the statistical analysis and drafted the manuscript. LB participated in the design of the studies, advised on data analysis and revised the manuscript. CO conceived of the study, participated in design, led the focus groups and revised the manuscript. SB participated in the design of the studies, was the principal supervisor of the doctoral thesis upon which this article was based and revised the manuscript. SS participated in the design of the study and revised the manuscript. All authors read and approved the final manuscript.

\section{Competing interests}

The authors declare that they have no competing interests.

Received: 8 November 2010 Accepted: 5 October 2011

Published: 5 October 2011

\section{References}

1. Masten AS: Ordinary magic: Resilience processes in development. American Psychologist 2001, 56(3):227-238.

2. Wyman P, Cowen E, Work W, Hoyt Meyers L, Magnus K, Fagen D: Caregiving and developmental factors differentiating young at-risk urban children showing resilient versus stress-affected outcomes: A replication and extension. Child Development 1999, 70(3):645-659.

3. Rutter M: Resilience concepts and findings: Implications for family therapy. The Association for Family Therapy and Systemic Practice 1999, 21:119-144.
4. Egeland B, Carlson E, Sroufe LA: Resilience as process. Development and Psychopathology 1993, 5(4):517-528.

5. Masten A: Resilience in developing systems: Progress and promise as the fourth wave rises. Development and Psychopathology 2007, 19(3):921.

6. Anthony EJ, Cohler BJ: The invulnerable child. New York: The Guilford Press; 1987.

7. Cicchetti D, Rogosch FA, Lynch M, Holt K: Resilience in maltreated children: Processes leading to adaptive outcome. Development and Psychopathology 1993, 5(4):629-647.

8. Garmezy N: Reflections and commentary on risk resilience and development. In Stress, risk and resilience in children and adolescents: Processes, mechanisms and interventions. Edited by: Haggerty R, Sherrod L, Garmezy N, Rutter M. Cambridge: Cambridge University Press; 1996:1-17.

9. Luthar S, Zigler E: Vulnerability and competence: A review of research on resilience in childhood. American Journal of Orthopsychiatry 1991, 61(1):6-22.

10. Olsson C, Bond L, Burns J, Vella-Broderick D, Sawyer S: Adolescent resilience: A concept analysis. Journal of Adolescence 2003, 26(1):1-11.

11. Connor KM, Davidson JR: Development of a new resilience scale: the Connor-Davidson Resilience Scale (CD-RISC). Depression and Anxiety 2003, 18(2):76-82.

12. Jew $\mathrm{CL}$, Green $\mathrm{KE}$, Kroger J: Development and validation of a measure of resiliency. Measurement and Evaluation in Counselling and Development 1999, 32(2):75-89.

13. Wagnild GM, Young HM: Development and psychometric evaluation of the Resilience Scale. Journal of Nursing Measurement 1993, 1(2):165-178.

14. Friborg $\mathrm{O}$, Hjemdal $\mathrm{O}$, Rosenvinge $\mathrm{JH}$, Martinussen $\mathrm{M}$ : A new rating scale for adult resilience: what are the central protective resources behind healthy adjustment? International Journal of Methods in Psychiatric Research 2003, 12(2):65-76.

15. Cicchetti D, Garmezy N: Prospects and promises in the study of resilience. Development and Psychopathology 1993, 5:497-502.

16. Luthar S, Doernberger $\mathrm{CH}$, Zigler E: Resilience is not a uni-dimensional construct: Insights from a prospective study of inner-city adolescents. Development and Psychopathology 1993, 5(4):703-717.

17. Gartland D: Resilience in adolescents: the development and preliminary psychometric testing of a new measure. Melbourne: Swinburne University; 2009.

18. Lynch M, Cicchetti D: An ecological-transactional analysis of children and contexts: The longitudinal interplay among child maltreatment, community violence and children's symptomatology. Development and Psychopathology 1998, 10:235-257.

19. Cicchetti D, Lynch M: Toward an ecological/transactional model of community violence and child maltreatment: consequences for children's development. Psychiatry 1993, 56(1):96-118.

20. Bond L, Toumbourou JW, Thomas L, Catalano RF, Patton G: Individual, Family, School, and Community Risk and Protective Factors for Depressive Symptoms in Adolescents: A Comparison of Risk Profiles for Substance Use and Depressive Symptoms. Prevention Science; New York 2005, 6(2):73.

21. Olsson C, Boyce M, Toumbourou J, Sawyer S: The role of peer support in facilitating psychosocial adjustment to chronic illness in adolescence. Clinical Child Psychology and Psychiatry 2005, 10(1):78-87.

22. Cadman D, Boyle M, Szatmari P, Offord DR: Chronic Illness, Disability, and Mental and Social Well-Being: Findings of the Ontario Child Health Study. Pediatrics 1987, 79(5):805-813.

23. Bennett DS: Depression among children with chronic medical problems: a meta-analysis. Journal of Pediatric Psychology 1994, 19(2):149-69.

24. Kliewer W: Children's coping with chronic illness. In Handbook of children's coping: Linking theory and intervention. Issues in clinical child psychology. Edited by: Wolchik SA, Sandler IN. New York: Plenum Press; 1997:275-300.

25. Lavigne JV, Faier-Routman J: Psychological adjustment to pediatric physical disorders: a meta-analytic review. Journal of Pediatric Psychology 1992, 17(2):133-57.

26. Madan-Swain A, Brown RT: Cognitive and psychosocial sequelae for children with acute lymphocytic leukemia and their families. Clinical Psychology Review 1991, 11(3):267-294.

27. Billings AG, Moos RH, Miller JJ, Gottlieb JE: Psychosocial adaptation in juvenile rheumatic disease: A controlled evaluation. Health Psychology 1987, 11(4):463-485. 
28. Garrison WT, McQuiston S: Chronic illness during childhood and adolescence: Psychological aspects. Newbury Park: Sage Publications; 1989.

29. Hanson CL, Onikul-Ross SR: Developmental issues in the lives of youths with insulin-dependent diabetes mellitus. In Child and adolescent disorders: Developmental and health psychology perspectives. Edited by: Morgan S, Okwumabua T, al e. Hillsdale, NJ: Lawrence Erlbaum Associates; 1990:201-240.

30. Owens EB, Shaw DS, Giovannelli J, Garcia MM, Yaggi K: Factors associated with behavioral competence at school among young boys from multiproblem low-income families. Early Education and Development 1999, 10(2):135-162

31. Buckner JC, Mezzacappa E, Beardslee WR: Characteristics of resilient youths living in poverty: the role of self-regulatory processes. Development \& Psychopathology 2003, 15(1):139-62.

32. Eisenberg N, Guthrie IK, Fabes RA, Reiser M, Murphy BC, Holgren R, Maszk P, Losoya S: The relations of regulation and emotionality to resiliency and competent social functioning in elementary school children. Child Development 1997, 68(2):295-311.

33. Shields A, Cicchetti D: Reactive aggression among maltreated children: The contributions of attention and emotion dysregulation. Journal of Clinical Child Psychology 1998, 27(4):381-395.

34. Sanson A, Smart D, Prior M, Oberklaid F: Precursors of hyperactivity and aggression. Journal of the American Academy of Child \& Adolescent Psychiatry 1993, 32(6):1207-1216.

35. Barocas R, Seifer R, Sameroff A, Andrews T, Croft R, Ostrow E: Social and interpersonal determinants of developmental risk. Developmental Psychology 1991, 27(3):479-488.

36. Cowen E, Work W, Wyman P, Parker G, Wannon M, Gribble P: Test comparisons among stress affected, stress resilient and non-classified fourth- through sixth-grade urban children. Journal of Community Psychology 1992, 20(July):200-214.

37. Shiner RL, Masten AS, Roberts JM: Childhood personality foreshadows adult personality and life outcomes two decades later. Journal of Personality 2003, 71(6):1145-1170.

38. Springer SA, Gastfriend DR: A pilot study of factors associated with resilience to substance abuse in adolescent sons of alcoholic fathers. Journal of Addictive Diseases 1995, 14(2):53-66.

39. Bolger KE, Patterson CJ: Sequelae of child maltreatment: Vulnerability and resilience. In Resilience and Vulnerability: Adaptation in the context of childhood adversities. Edited by: Luthar S. New York, NY, US: Cambridge University Press; 2003:156-181.

40. Liberman RP, Mueser KT, Wallace CJ, Jacobs HE, Eckman T, Massel HK: Training Skills in the Psychiatrically Disabled: Learning Coping and Competence. Schizophrenia Bulletin 1986, 12(4):631-647.

41. Hartup WW: Peer relations. In Socialisation, personality and social development. Edited by: Hetherington EM. New York: Wiley; 1983:103-196.

42. Turner R, Frankel B, Levin D: Social Support: Conceptualisation, measurement and implications for mental health. Research in Community and Mental Health 1983, 3:67-111.

43. Luthar S: Vulnerability and resilience: A study of high-risk adolescents. Child Development 1991, 62(3):600-616.

44. Parker G, Cowen E, Work W, Wyman P: Test correlates of stress-resilience among urban school children. Journal of Primary Prevention 1990, 11(1):19-35

45. Wyman P, Cowen E, Work W, Kerley J: The role of children's future expectations in self esteem functioning and adjustment to life stress: A prospective study of urban at-risk children. Development and Psychopathology 1993, 5(4):649-661.

46. Costa FM, Jessor R, Turbin MS: Transition into adolescent problem drinking: The role of psychosocial risk and protective factors. Journal of Studies on Alcohol 1999, 60(4):480-490.

47. Werner EE, Smith RS: Overcoming the odds: High risk children from birth to adulthood. Ithaca, NY, US: Cornell University Press; 1992.

48. Wyman P, Cowen E, Work W, Raoof A, Gribble P, Parker G, Wannon M: Interviews with children who experienced major life stress: Family and child attributes that predict resilient outcomes. Journal of the American Academy of Child and Adolescent Psychiatry 1992, 31(5):904-910.

49. Fergusson D, Horwood LJ: Resilience to childhood adversity: Results of a 21-year study. In Resilience and Vulnerability: Adaptation in the context of childhood adversities. Edited by: Luthar S. Cambridge: Cambridge University Press; 2003:130-155.

50. Magnus KB, Cowen EL, Wyman PA, Fagen DB, Work WC: Correlates of resilient outcomes among highly stressed African-American and White urban children. Journal of Community Psychology 1999, 27(4):473-488.

51. Fergusson D, Lynskey M: Adolescent resiliency to family adversity. Journal of Child Psychology and Psychiatry 1996, 37(3):281-292.

52. Masten AS, Hubbard JJ, Gest SD, Tellegen A, Garmezy N, Ramirez M: Competence in the context of adversity: pathways to resilience and maladaptation from childhood to late adolescence. Development and Psychopathology 1999, 11(1):143-169.

53. Seifer R, Sameroff AJ, Baldwin CP, Baldwin A: Child and family factors that ameliorate risk between 4 and 13 years of age. Journal of the American Acadamy of Child and Adolescent Psychiatry 1992, 31(5):893-903.

54. Egeland B: Mediators of the effects of child maltreatment on developmental adaptation in adolescence. In Developmental Perspectives On Trauma: Theory, Research, And Intervention. Edited by: Cicchetti D, Toth SL. Rochester, NY, US: University of Rochester Press; 1997:403-434.

55. Beardslee WR: The role of self-understanding in resilient individuals: the development of a perspective. American Journal of Orthopsychiatry 1989, 59(2):266-78

56. Dumont M, Provost MA: Resilience in adolescents: Protective role of social support, coping strategies, self-esteem, and social activities on experience of stress and depression. Journal of Youth and Adolescence 1999, 28(3):343-363.

57. Kline T: Psychological Testing: A Practical Approach to Design and Evaluation. London: SAGE Publications; 2005.

58. Streiner D, Norman G: Health measurement scales: A practical guide to their development and use. Oxford: Oxford University Press; 21996.

59. Bess KD: Psychological sense of community: Theory, research, and application. In Psychological sense of community: research, applications, and implications. Edited by: Fisher AT, Sonn CC, Bishop BJ. New York, NY, US: Kluwer Academic/Plenum Publishers; 2002:3-22.

60. Perkins DD, Long DA: Psychological sense of community: Research, applications and implications. In Neighborhood sense of community and social capital: A multi-level analysis. Edited by: Adrian T. Fisher, Christopher C Sonn, Bishop BJ. New York, US: Kluwer Academic/Plenum Publishers; 2002:291-318.

61. Coleman JS: Social capital in the creation of human capital. The American Journal of Sociology 1988, 94(Supp):S95.

62. Cohen R: Psychological testing and assessment: an introduction to tests and measurement. Boston: McGraw-Hill; 62005.

63. Cicchetti D, Ackerman B, Izard C: Emotions and emotion regulation in developmental psychopathology. Development and Psychopathology 1995, 7(1):1-10.

64. Schwartz D, Proctor L: Community Violence Exposure and Children's Social Adjustment in the School Peer Group: The Mediating Roles of Emotion Regulation and Social Cognition. Journal of Consulting and Clinical Psychology 2000, 68(4):670.

65. Wilson BJ, Gottman JM: Attention - the shuttle between emotion and cognition: Risk, resiliency, and physiological bases. In Stress, coping and resiliency in children and families. Edited by: Hertherington EM, Blechman E. Hillsdale, NJ: Lawrence Erlbaum Associates; 1996:245.

66. Luthar S, Brown P: Maximizing resilience through diverse levels of inquiry: Prevailing paradigms, possibilities, and priorities for the future. Development and Psychopathology 2007, 19(3):931.

\section{Pre-publication history}

The pre-publication history for this paper can be accessed here: http://www.biomedcentral.com/1471-2288/11/134/prepub

doi:10.1186/1471-2288-11-134

Cite this article as: Gartland et al.: Development of a multi-dimensional measure of resilience in adolescents: the Adolescent Resilience Questionnaire. BMC Medical Research Methodology 2011 11:134. 